\title{
Ultrafast Hydro-Micromechanical Synthesis of Calcium Zincate: Structural and Morphological Characterizations
}

\author{
Vincent Caldeira, ${ }^{1,2}$ Laurent Jouffret, ${ }^{3}$ Julien Thiel, ${ }^{4}$ François R. Lacoste, ${ }^{4}$ Saïd Obbade, ${ }^{1,2}$ \\ Laetitia Dubau, ${ }^{1,2}$ and Marian Chatenet ${ }^{1,2,5}$ \\ ${ }^{1}$ Université Grenoble Alpes, LEPMI, 38000 Grenoble, France \\ ${ }^{2}$ CNRS, LEPMI, 38000 Grenoble, France \\ ${ }^{3}$ ICCF, Institut de Chimie de Clermont Ferrand, UMR 6296, Université Blaise Pascal, 63178 Aubière, France \\ ${ }^{4}$ EASYL SA, 712 avenue de Faucigny, 74130 Bonneville, France \\ ${ }^{5}$ French University Institute, Paris, France \\ Correspondence should be addressed to Vincent Caldeira; vincent.caldeira@lepmi.grenoble-inp.fr
}

Received 3 January 2017; Revised 14 March 2017; Accepted 27 March 2017; Published 11 April 2017

Academic Editor: Miguel A. Garcia

Copyright (C) 2017 Vincent Caldeira et al. This is an open access article distributed under the Creative Commons Attribution License, which permits unrestricted use, distribution, and reproduction in any medium, provided the original work is properly cited.

\begin{abstract}
Calcium zincate is a compound with a large panel of application: mainly known as an advantageous replacement of zinc oxide in negative electrodes for air-zinc or nickel-zinc batteries, it is also used as precursor catalyst in biodiesel synthesis and as antifungal compound for the protection of limestone monuments. However, its synthesis is not optimized yet. In this study, it was elaborated using an ultrafast synthesis protocol: Hydro-Micromechanical Synthesis. Two other synthesis methods, Hydrochemical Synthesis and Hydrothermal Synthesis, were used for comparison. In all cases, the as-synthesized samples were analyzed by X-ray diffraction, scanning electron microscopy, and LASER diffraction particle size analysis. Rietveld method was used to refine various structural parameters and obtain an average crystallite size, on a Hydro-Micromechanical submicronic sample. X-ray single crystal structure determination was performed on a crystal obtained by Hydrochemical Synthesis. It has been shown that regardless of the synthesis protocol, the prepared samples always crystallize in the same crystal lattice, with $\mathrm{P} 2{ }_{1} / \mathrm{c}$ space group and only differ from their macroscopic textural parameters. Nevertheless, only the Hydro-Micromechanical method is industrially scalable and enables a precise control of the textural parameters of the obtained calcium zincate.
\end{abstract}

\section{Introduction}

During the last decades, thorough research has been conducted on several synthesis routes of $\mathrm{Ca}(\mathrm{OH})_{2}, 2 \mathrm{Zn}(\mathrm{OH})_{2}$, $2 \mathrm{H}_{2} \mathrm{O}$ calcium zincate; the performances of the obtained compounds were evaluated in the field of zinc secondary alkaline accumulators, biodiesel production [1-5], and limestone-monument protection [6, 7]. In 1986, Sharma established a first physicochemical identification of calcium zincate including, among other, its thermal behavior using thermogravimetric analysis (TGA), overall shape in scanning electron microscopy (SEM), and its powder X-ray diffraction pattern [8]. A few years later, Stahl and Jacobs described the crystal structure of this compound, which falls into the family of monoclinic lattices [9].
In 2003, Zhu et al. used a mechanochemical process to synthesize calcium zincate without using alkaline solution [10]. They described a process which leads to two types of crystals with approximately the same crystal parameters compared to those found by Stahl and Jacobs, except for the beta value of the monoclinic lattice. Zhu et al. stated that a first compound with $\beta=101.92$ appears for short durations of milling, whereas another one with $\beta=78.02$ appears after a prolonged milling time. In another study, Yang et al. compared a ball-milling method and an alkaline-chemical method [11]. They found that the calcium zincate crystal could be composed by two or three water molecules, depending on the synthesis process, but in all cases, the samples showed a similar crystal structure. In 2008, Wang et al. obtained the crystal $\mathrm{Ca}(\mathrm{OH})_{2}, 2 \mathrm{Zn}(\mathrm{OH})_{2}, 2 \mathrm{H}_{2} \mathrm{O}$ with 
approximately the same characteristics as Zhu et al., using only thermal treatment of $\mathrm{ZnO}$ and $\mathrm{Ca}(\mathrm{OH})_{2}$ suspension in water without strong alkaline solution [12]. Calcium zincate could also be synthesized via a microwave-assisted method $[13,14]$. In 2012, Li and Zhou claimed to have synthesized the calcium zincate with a beta value $\beta=78.0$ and stated that the perfect crystal shape should always have the chemical expression including two water molecules [15].

This short and selected literature review demonstrates that some confusions remain regarding the chemistry and structure of calcium zincate. Furthermore, until now, no scalable synthesis route for calcium zincate exists, yet, thereby impeding its potential industrialization. The present study addresses these two issues: calcium zincate was prepared through a high-efficiency and scalable method named Hydro-Micromechanical Synthesis (HMMS) and patented by EASYL [16]. Two other methods, the Hydrochemical Synthesis (HCS) and Hydrothermal Synthesis (HTS), both inspired from literature, were used for comparison, in order to establish a unified description and characteristic pattern of calcium zincate, regardless of its synthesis protocol.

\section{Experimental Details}

2.1. High-Efficiency Hydro-Micromechanical Synthesis (HMMS). Calcium zincate powders were synthesized by a "HydroMicromechanical Synthesis" (HMMS), implemented at EASYL Company (France). This synthesis method is derived from their patent [16]. More specifically, two grades of zincate powders prepared by EASYL, differing only by their residence time in the reactor, an easily tuned experimental parameter, were thoroughly characterized.

The method basically consists of introducing a stoichiometric $\left[2 \mathrm{ZnO}+\mathrm{Ca}(\mathrm{OH})_{2}\right]$ aqueous suspension through a high-efficiency continuous-flow miller filled by an appropriate amount of milling balls (proprietary). The formation of calcium zincate powder by the HMMS method can be described by the following reaction (1):

$$
\begin{aligned}
& 2 \mathrm{ZnO}_{(\mathrm{s})}+\mathrm{Ca}(\mathrm{OH})_{2(\mathrm{~s})}+4 \mathrm{H}_{2} \mathrm{O} \\
& \longrightarrow \mathrm{Ca}(\mathrm{OH})_{2}, 2 \mathrm{Zn}(\mathrm{OH})_{2}, 2 \mathrm{H}_{2} \mathrm{O}_{(\mathrm{s})}
\end{aligned}
$$

For this communication, the flow used was $30 \mathrm{~L} \mathrm{~h}^{-1}$ with a $250 \mathrm{~g} \mathrm{~L}^{-1}$ suspension. The method is denominated "ultrafast," owing to the very low residence time of the reactant in the reactor, scalable from a few seconds to a few minutes. In the present case, two samples were synthesized with a residence time of $7 \mathrm{~s}$ (micronic HMMS) and $144 \mathrm{~s}$ (Submicronic HMMS), respectively. This process enables producing highquality calcium zincate at low cost and industrial scale.

2.2. Hydrochemical Synthesis in $4 \mathrm{M} \mathrm{KOH}$ (HCS). Inspired from the synthesis protocol of Li and Zhou [15], calcium zincate powders were also synthesized by the so-called "Hydrochemical Synthesis" method in alkaline solution. Firstly, $\mathrm{ZnO}$ was added to a $4 \mathrm{M} \mathrm{KOH}$ solution until saturation (2).

$$
2 \mathrm{ZnO}_{(\mathrm{s})}+4 \mathrm{OH}^{-}, \mathrm{K}^{+}+2 \mathrm{H}_{2} \mathrm{O} \longrightarrow 2 \mathrm{Zn}(\mathrm{OH})_{4}{ }^{2-}, 2 \mathrm{~K}^{+}
$$

The solution was brought to $313 \mathrm{~K}$, and $\mathrm{Ca}(\mathrm{OH})_{2}$ was then added in stoichiometric concentration to form $\mathrm{Ca}(\mathrm{OH})_{2}$, $2 \mathrm{Zn}(\mathrm{OH})_{2}, 2 \mathrm{H}_{2} \mathrm{O}_{(\mathrm{s})}(3)$.

$$
\begin{aligned}
& 2 \mathrm{Zn}(\mathrm{OH})_{4}{ }^{2-}, 2 \mathrm{~K}^{+}+\mathrm{Ca}(\mathrm{OH})_{2(\mathrm{~s})}+2 \mathrm{H}_{2} \mathrm{O} \\
& \longrightarrow \mathrm{Ca}(\mathrm{OH})_{2}, 2 \mathrm{Zn}(\mathrm{OH})_{2}, 2 \mathrm{H}_{2} \mathrm{O}_{(\mathrm{s})}+4 \mathrm{OH}^{-}, \mathrm{K}^{+}
\end{aligned}
$$

After few days at $313 \mathrm{~K}$, the suspension was cooled down to ambient temperature. At rest, the powder naturally decanted off due to gravity. The liquid phase above was removed and the remaining powder was dried at $323 \mathrm{~K}$ in an oven containing a $\mathrm{CO}_{2}$ trap to prevent eventual carbonation.

2.3. Hydrothermal Synthesis (HTS). The last calcium zincate powders were synthesized by a "Hydrothermal Synthesis" method inspired by the literature [12]. Under continuous stirring, stoichiometric amounts of $\mathrm{Ca}(\mathrm{OH})_{2}$ and $\mathrm{ZnO}$ were added to a reaction vessel containing an excess of distilled water. The reaction temperature was controlled at $348 \pm 1 \mathrm{~K}$ during $24 \mathrm{~h}$, followed by cooling down to ambient temperature. The formation of calcium zincate powders by the HTS method follows the same reaction equation as for HMMS (1).

As for the HCS method, calcium zincate crystals were retrieved by simple decantation and dried.

2.4. Characterizations Methods. In this study, two grades of calcium zincate, prepared by HMMS synthesis methods, have been compared with two other grades inspired from the literature aiming to determine if calcium zincate owns multiple crystal structure and if it depends on the synthesis protocol.

Using a well-shaped colorless single crystal prepared by the HCS method, single crystal X-ray diffraction data were collected on a Bruker APEXII CCD diffractometer with the use of the graphite monochromatized MoK $\alpha$ radiation $(\lambda$ $=0.71073 \AA$ ). A data collection strategy consisting of $\varphi$ and $\omega$ scans was devised using COSMO in APEXII (Bruker, SADABS, APEX2, and SAINT, Bruker AXS Inc., Madison, Wisconsin, USA, 2008). The data frames were $0.5^{\circ}$ in width and taken at a detector distance of $40 \mathrm{~mm}$ with exposure time of $10 \mathrm{~s}$ per frame. XPREP was used for space group determination and to create file for SHELXTL. The structures were solved with SHELXS and refined by full matrix leastsquares on $F^{2}$ with SHELXL of the SHELX package [17].

For each powder sample (including the one characterized by single crystal X-ray diffraction), powder X-ray diffraction data have been collected with a X'Pert PRO PANalytical $\theta / 2 \theta$ diffractometer equipped by $\mathrm{CuK} \alpha$ radiation, using BraggBrentano geometry, in steps of $0.017^{\circ}$ and a counting time of $0.008 \mathrm{~s}$ per step, within an angular range from 10 to $100^{\circ}$ for the refinement. The lattice parameters for different samples were refined from powder X-ray diffraction data, using the "pattern matching" option of Fullprof suite program $[18,19]$; only the profile parameters (cell dimensions, peak shapes, background, zero-point correction, and symmetry) have been refined. The peak shape was described by a PseudoVoigt function with an asymmetry correction at low angles. To describe the angular dependence of the peak full-width 


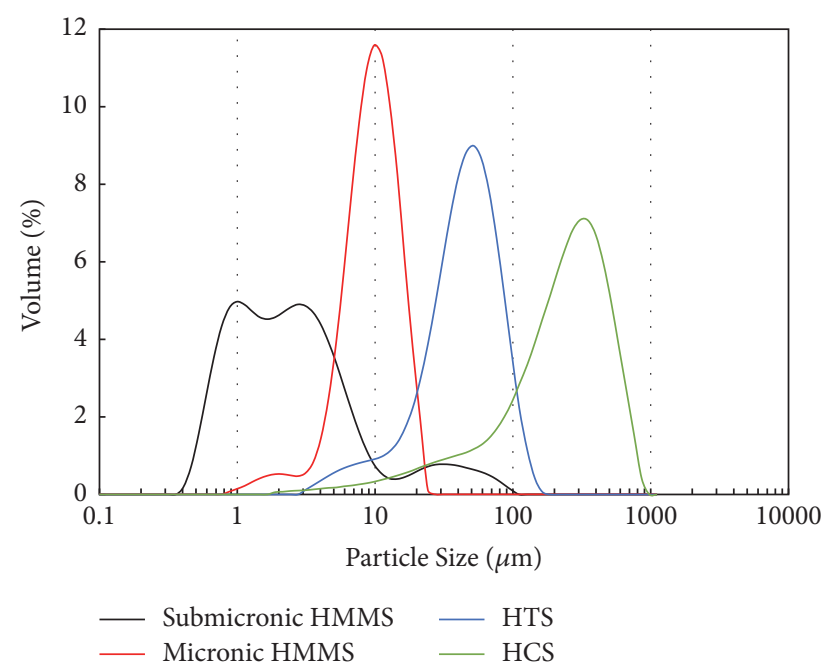

FIgURE 1: Particle size distribution of calcium zincate crystals synthesized by the HCS method (green), HTS method (blue), Micronic HMMS (red), and Submicronic HMMS (black).

at half-maximum $(H)$, the formulation of Caglioti et al. was used: $H^{2}=U \tan ^{2} \theta+V \tan \theta+W$ where $U, V$, and $W$ parameters were refined in the process [20].

For the Submicronic HMMS calcium zincate sample, the crystal structure has been refined by Rietveld method using powder X-ray diffraction data [21, 22].

The particle size distribution was also measured by LASER particle size analysis (PSA) using a Mastersizer 3000E (Malvern Instruments Ltd., UK) instrument sensitive to particle sizes in the range from 0.1 to $1000 \mu \mathrm{m}$.

The morphology of each synthesized calcium zincate powders was analyzed by a FEG-SEM (Ultra 55, Carl Zeiss, Germany) using a secondary electron in-lens detector and working at $\mathrm{WD}=6 \mathrm{~mm}$ with $2 \mathrm{KeV}$ to maximize the image resolution at low beam energies.

\section{Results and Discussion}

3.1. Particle Size Distribution and Morphology of the AsSynthesized Calcium Zincate Samples. The particle size distributions of the samples prepared by the HMMS, HTS, and HCS methods are shown in Figure 1. Each protocol leads to a different particle distribution range with the same dispersion profile, except for the smallest grade, which presents a bimodal dispersion. The particles of the HTS powder are mostly located within the size range of [10-200] $\mu \mathrm{m}$ while those of the HCS fall within the size range of [70-1000] $\mu \mathrm{m}$.

The HMMS synthesis method yields smaller calcium zincate particles with $10 \pm 2 \mu \mathrm{m}$ average size for the micronic sized one and leads to the most homogeneous calcium zincate powder within the minimum synthesis time. Besides it also could lead to smaller particles denoted HMMS submicronic.

Figure 2 shows the FEG-SEM micrographs of the calcium zincate powders synthesized using the HCS, HTS, and HMMS methods (2 grades). Note that the scales of the images are different owing to the significant differences in particle size induced by various synthesis protocols.
Calcium zincate particles synthesized from the Hydrochemical Synthesis (HCS) method are shown in Figures 2(a) and 2(b). In this case and according to the literature [15], the obtained powder is composed of large regular crystal shapes. The size of the selected one in this image is approximately $200 \mu \mathrm{m}$ long.

After the Hydrothermal Synthesis (HTS) performed during $24 \mathrm{~h}$ at $75^{\circ} \mathrm{C}$, the calcium zincate crystals, shown in Figures 2(c) and 2(d), consist of tetragonal-like particle with a thickness of $20 \mu \mathrm{m}$ in the center (it is thinner on the tips).

In supporting information (S.I.1. in Supplementary Material available online at https://doi.org/10.1155/2017/7369397) are presented examples of crystal thickness measurements.

The particles are surrounded by some, much smaller, unreacted $\mathrm{ZnO}$ particles, as determined by X-EDS elemental mapping analyses (supporting info S.I.2).

The HMMS method produces lozenge-platelet calcium zincate particle (Figure 2(e)). Among the particles analyzed, the thickness was measured and seems to be homogeneous (ca. $1 \mu \mathrm{m}$, S.I.3.).

Figures 2(g) and 2(h) show representative agglomerated submicronic calcium zincate particles synthesized through the HMMS method after $144 \mathrm{~s}$ of residence time. However, on those images, the particles are much smaller than for the two previous samples and essentially uneven in shape; some illdefined micronic lozenge-like particles are still found among the agglomerates.

The HMMS method yields submicronic particles for prolonged (144 s) milling time, by pulverization of the initial synthesized micronic HMMS crystals (7 s milling time). Except for the submicronic material, all of the crystals synthesized seem to grow as a superposition of layers from the middle to the tips of the particle, and the experimental protocol is determinant for the final particle size. Regardless of the synthesis protocol, the tetragonal shape seems to be the favored one.

3.2. Structural Characterization of Different Calcium Zincate Samples. The powder diffractograms presented in Figure 3 show that Submicronic HMMS (a), Micronic HMMS (b), HTS (c), and HCS samples (d) are all well-crystallized materials, regardless of their external morphology and particle size. In particular, Figures 3(b) and 3(c) patterns clearly show the preferential orientation of some crystallites due to their arrangement during the formation of the calcium zincate particles imaged in Figure 2. This preferential orientation is noticed by a huge variation in the intensity of the (100) and (200) reflections at $2 \theta=14.14^{\circ}$ and $28.57^{\circ}$, respectively. The preferential orientation follows the $\vec{a}$ direction, which means that the planar surface of calcium zincate crystals is composed by the plane $(\vec{b}, \vec{c})$.

The different refined patterns presented in Figure 3 reveal the very small amount of initial $\mathrm{ZnO}$ oxide, in perfect agreement with the presence of the small particles observed at the surface of the zinc FEG-SEM images (Figure 2). The refined results reported in Table 1 enable stating that all the samples are well-crystallized calcium zincate, according to their similar lattice parameters. They all crystallize in monoclinic symmetry and $\mathrm{P} 2_{1} / \mathrm{c}$ space group, with $\beta$ angle about $102^{\circ}$, in full agreement with the data from Stahl and Jacobs [9]. 


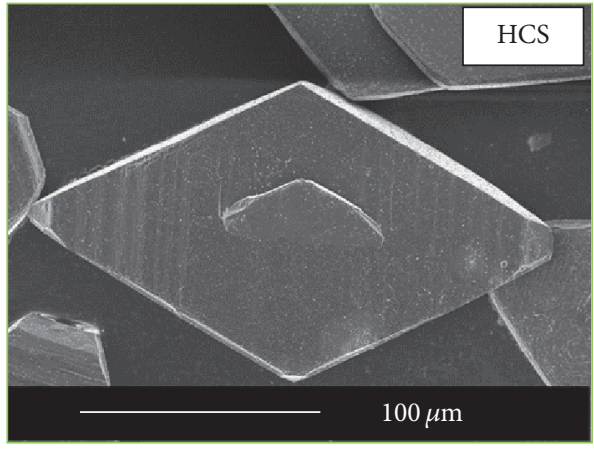

(a)

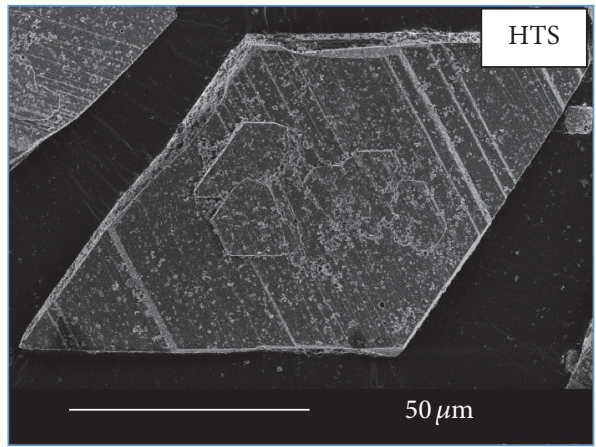

(c)

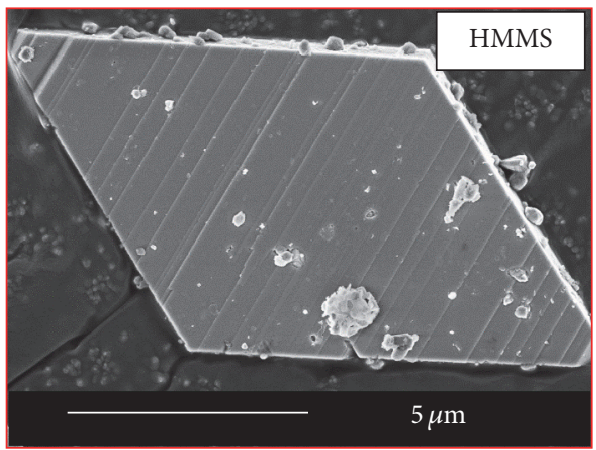

(e)

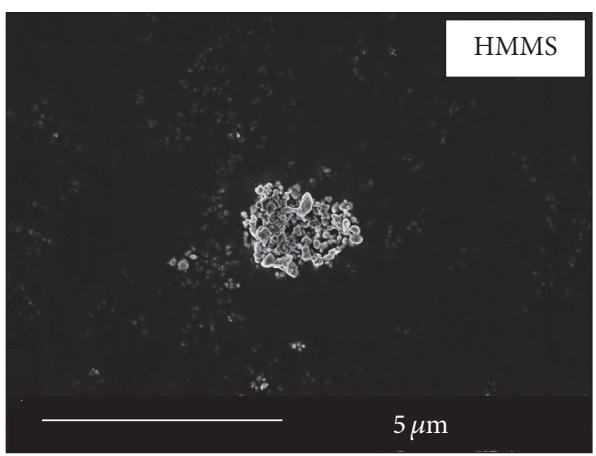

(g)

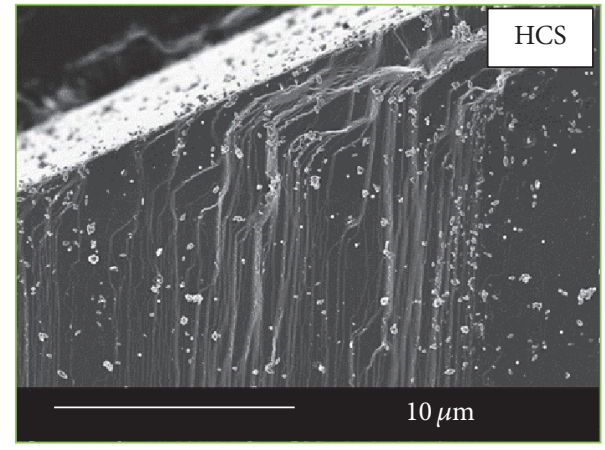

(b)

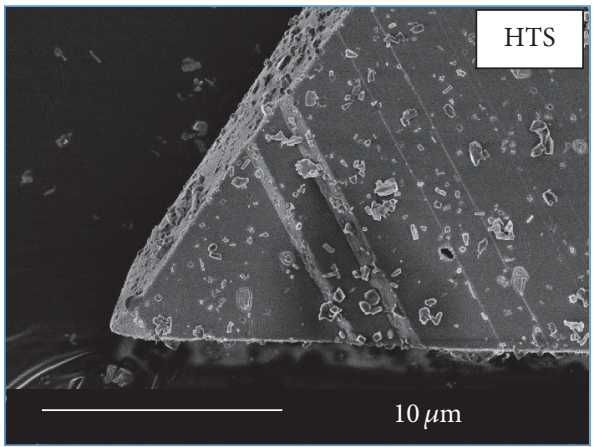

(d)

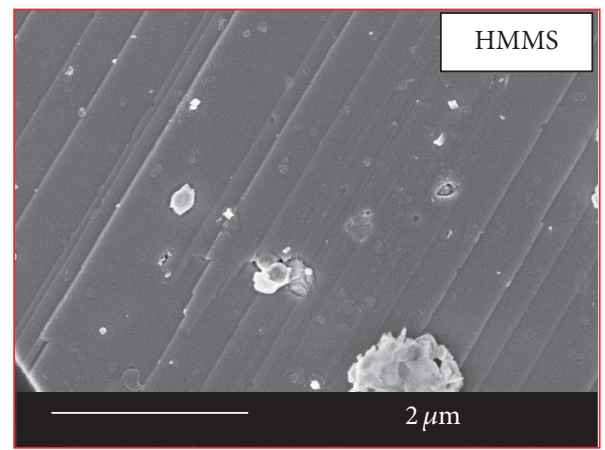

(f)

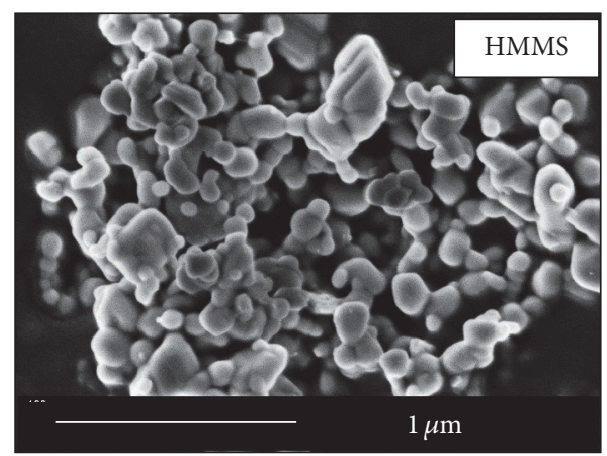

(h)

FIGURE 2: FEG-SEM micrographs of calcium zincate large crystals synthesized by the HCS method ((a), (b), green), HTS particles ((c), (d), blue), micronic HMMS ((e), (f), red), and Submicronic HMMS ((g), (h), black). 


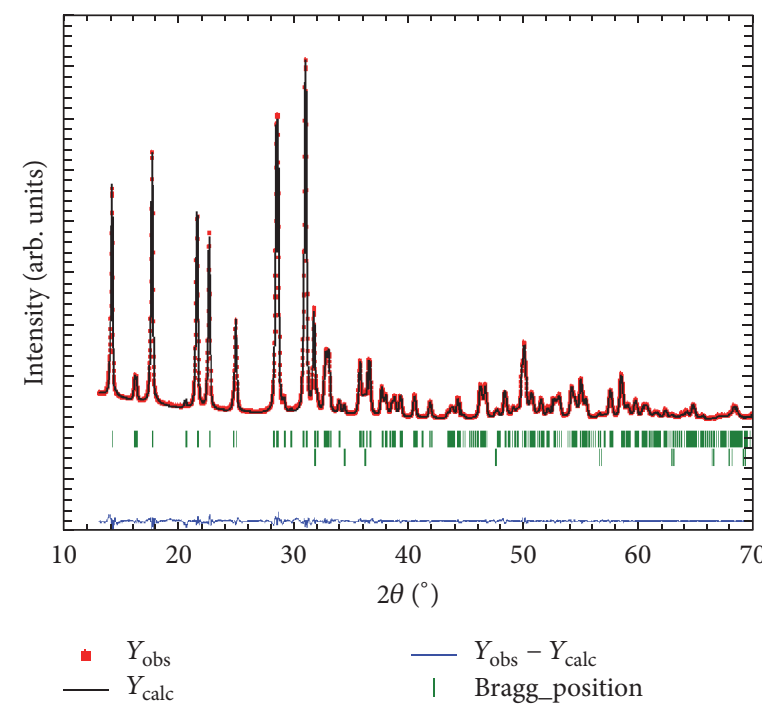

(a)

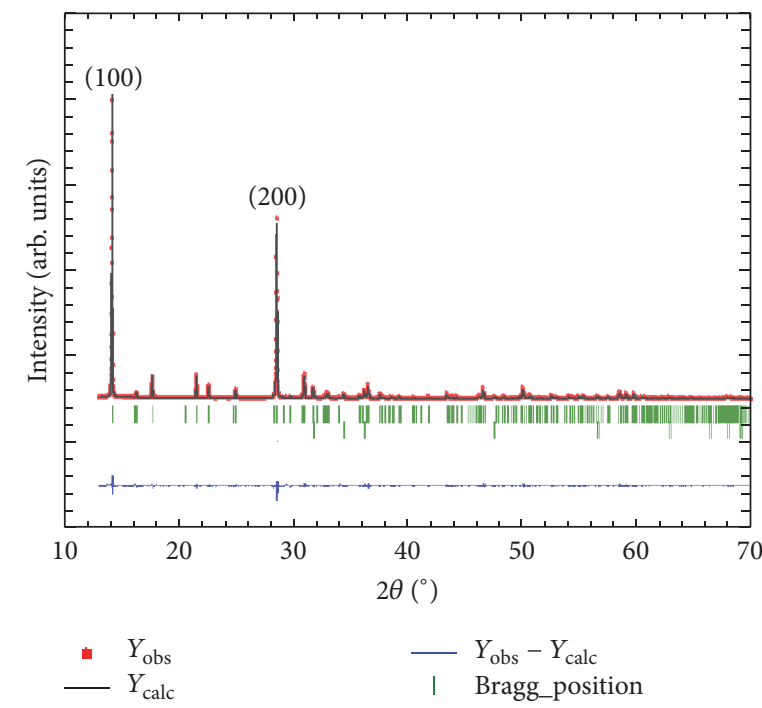

(c)

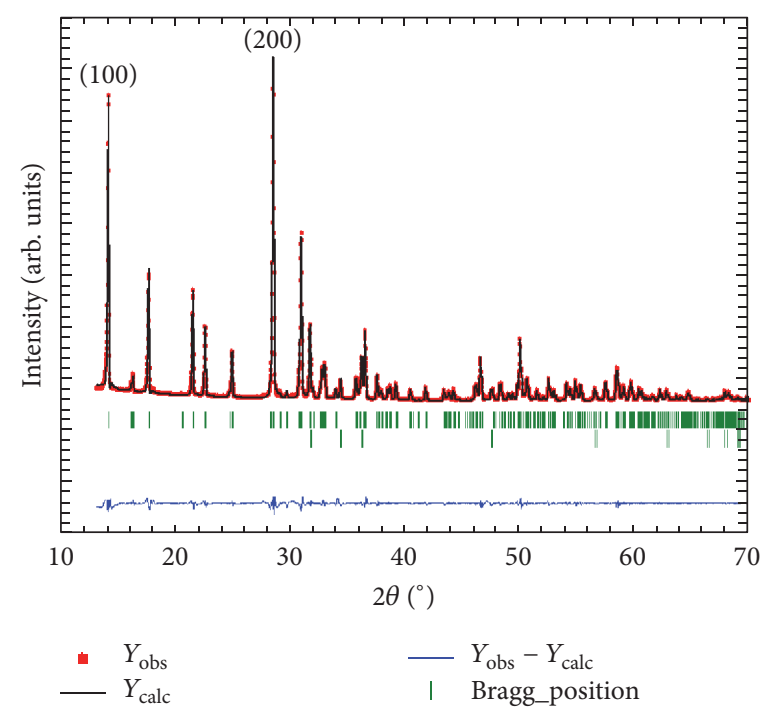

(b)

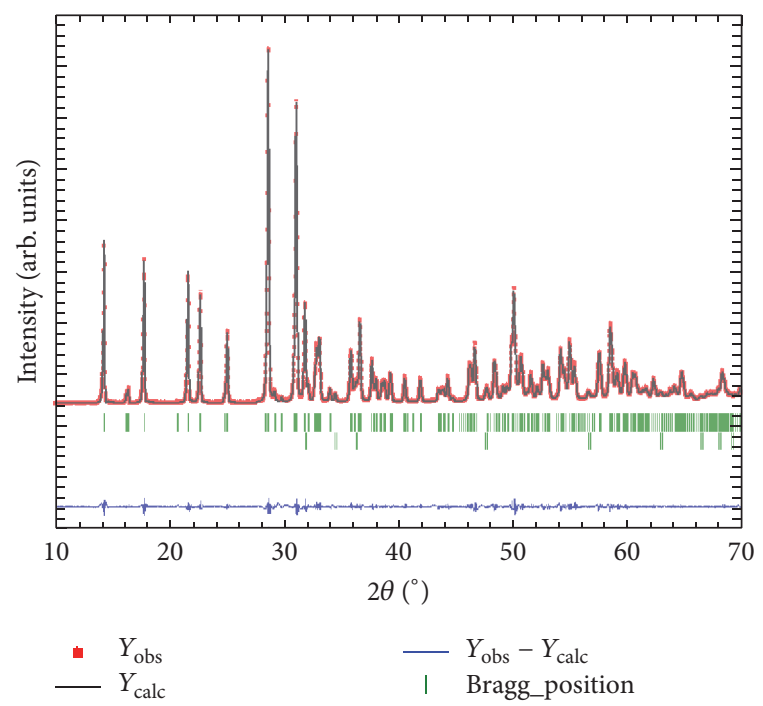

(d)

FIGURE 3: Experimental and calculated patterns determined by Rietveld refinement of Submicronic HMMS (a), Micronic HMMS (b), HTS (c), and calcium zincate compound and crystal structure obtained from a HCS single crystal X-ray diffraction data (d). $Y_{\text {obs }}$ and $Y_{\text {calc }}$ are the diffraction intensities observed experimentally and calculated, respectively; $Y_{\text {obs }}-Y_{\text {calc }}$ is the difference between these two values.

In the monoclinic symmetry, the $\beta$ angle can be considered as $\beta_{1}=102^{\circ}$ or $\beta_{2}=78^{\circ}$ taking into account that they are just complementary angles since $102^{\circ}=180^{\circ}-78^{\circ}$. There is only a single calcium zincate structure and the difference between these two values noted in the literature reside in the choice of the origin. For each sample, the agreement between observed and calculated data was very good, as indicated by the reliability factors summarized in Table 1 and by the plot of observed and calculated patterns represented in Figures 3(a) $-3(\mathrm{~d})\left(Y_{\text {obs }}-Y_{\text {calc }}\right.$ is always negligible).

3.3. Crystal Structure Refinement Determination of HCS and Submicronic HMMS Samples. The precise crystal structure determination has been carried out at low temperature
( $100 \mathrm{~K})$ on the HCS crystal presented in Figure 4 using single crystal X-ray diffraction technique.

All the details related to data collection and structure refinement parameters are mentioned in Tables 2 and 3. The lattice parameters obtained by single crystal analysis fit very well with those refined using powder X-ray diffraction data in Table 1.

A schematic representation of the monoclinic crystal structure of $\mathrm{CaZn}_{2}(\mathrm{OH})_{6}, 2 \mathrm{H}_{2} \mathrm{O}$ compound is displayed in Figure 5 and the atomic positions and equivalent isotropic thermal displacement obtained with single crystal refinement are added in Table 4 (bold).

Rietveld refinement was applied on X-ray powder diffraction data of Submicronic HMMS calcium zincate sample 


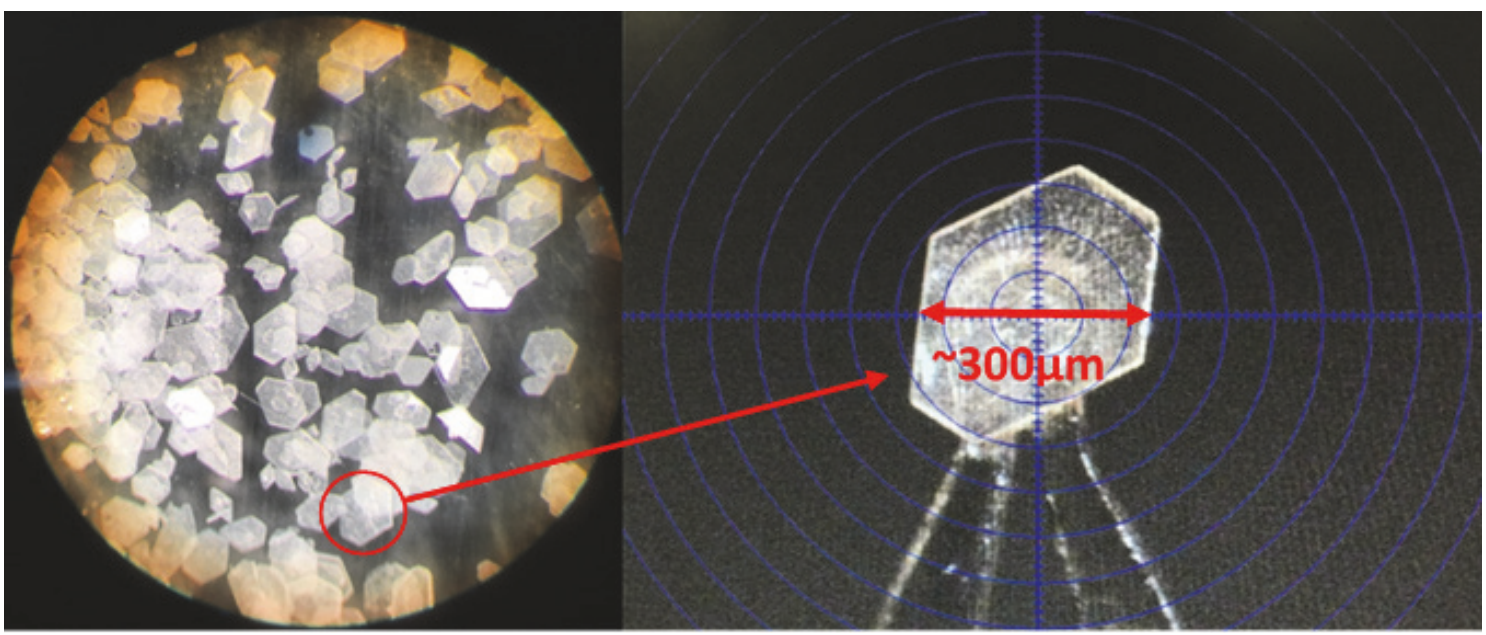

FIGURE 4: Frame of HCS single crystal used for crystal structure determination.

TABLE 1: Lattices parameters and reliability factors of refinements $\left(R_{\mathrm{p}}=\right.$ pattern factor, $R_{\mathrm{wp}}=$ weighted pattern factor, and $R_{\exp }=$ expected pattern factor).

\begin{tabular}{lcccc}
\hline Samples & $\begin{array}{c}\text { Submicronic } \\
(\mathrm{HMMS})\end{array}$ & $\begin{array}{c}\text { Micronic } \\
(\mathrm{HMMS})\end{array}$ & $\begin{array}{c}\text { Tetragonal } \\
(\mathrm{HTS})\end{array}$ & $\begin{array}{c}\text { Large } \\
\text { tetragonal } \\
(\mathrm{HCS})\end{array}$ \\
\hline \multicolumn{5}{c}{ Cell parameters } \\
$b / \AA$ & $6.3813(1)$ & $6.3831(1)$ & $6.3822(1)$ & $6.38312(7)$ \\
$c / \AA$ & $10.9601(2)$ & $10.9652(1)$ & $10.9664(1)$ & $10.9668(1)$ \\
$\beta l^{\circ}$ & $5.7553(1)$ & $5.7579(1)$ & $5.7581(1)$ & $5.75770(7)$ \\
& $101.898(1)$ & $101.899(1)$ & $101.902(1)$ & $101.900(1)$ \\
$R_{\mathrm{p}}$ & 2.26 & $R$-factors & & \\
$R_{\mathrm{wp}}$ & 3.11 & 3.61 & 9.93 & 2.85 \\
$R_{\exp }$ & 1.78 & 5.55 & 13.0 & 4.00 \\
\hline
\end{tabular}

TABLE 2: Single crystal data for CaZn2(OH $)_{6}, 2 \mathrm{H}_{2} \mathrm{O}$.

\begin{tabular}{|c|c|}
\hline Chemical formula & $\mathrm{CaZn} 2(\mathrm{OH})_{6}, 2 \mathrm{H}_{2} \mathrm{O}$ \\
\hline Formula weight & $308.91 \mathrm{~g} / \mathrm{mol}$ \\
\hline Crystal Temperature & $100(2) \mathrm{K}$ \\
\hline X-ray Wavelength & $0.71073 \AA$ \\
\hline Crystal size & $0.214 \times 0.536 \times 0.662 \mathrm{~mm}$ \\
\hline Crystal system & Monoclinic \\
\hline Space group & $\mathrm{P} 2_{1} / \mathrm{c}$ \\
\hline Unit cell dimensions & $\begin{array}{c}a=6.3690(7) \AA, \alpha=90^{\circ} \\
b=10.9236(13) \AA, \beta=102.272(4)^{\circ} \\
c=5.7437(6) \AA, \gamma=90\end{array}$ \\
\hline Volume & $390.47(8) \AA^{3}$ \\
\hline Unit cell formula number: $Z$ & 2 \\
\hline Density (calculated) & $2.627 \mathrm{~g} / \mathrm{cm}^{3}$ \\
\hline Absorption coefficient & $6.800 \mathrm{~mm}^{-1}$ \\
\hline$F(000)$ & 308 \\
\hline
\end{tabular}

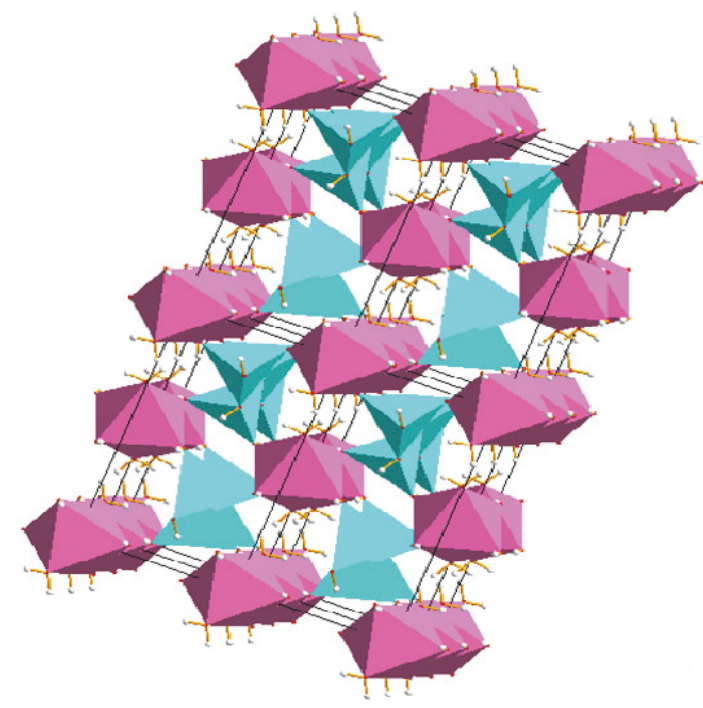

$\mathrm{Zn}$

$\mathrm{Ca}$

Figure 5: Projection view of $\mathrm{CaZn}_{2}(\mathrm{OH})_{6}, 2 \mathrm{H}_{2} \mathrm{O}$ crystal structure along the $\vec{c}$ axis.

without preferential orientation. The profile fits was also carried out using a Thompson-Cox-Hasting profile, allowing the simultaneous calculation of nanometric particle size $(D$ $=38.6(1) \mathrm{nm})$ and strain $(\eta=0.24 \%)$. The purity of this product is close to $99 \%$ with less than $1 \%$ of $\mathrm{ZnO}$ impurities. Atomic positions and isotropic thermal displacement parameters were also added in Table 4 (italic) and compared to those obtained by single crystal refinement Table 4 (bold). Comparison between these two compounds confirms that they are crystallized in exactly the same crystal structure. 
TABLE 3: Data collection and single crystal structure refinement parameters for $\mathrm{CaZn}_{2}(\mathrm{OH})_{6}, 2 \mathrm{H}_{2} \mathrm{O}$.

Theta range for data collection

Index ranges

Reflections collected

Independent reflections

Coverage of independent reflections

Absorption correction

Refinement method

Refinement program

Function minimized

Data/restraints/parameters

Goodness-of-fit on $F^{2}$

Final $R$ indices

Weighting scheme

Largest diff. peak and hole

RMS deviation from mean
3.27 to $33.18^{\circ}$

$-9 \leq h \leq 9,-16 \leq k \leq 16,-8 \leq l \leq 8$

24958

$1497[R($ int $)=0.0471]$

$100.0 \%$

Numerical

Full-matrix least-squares on $F^{2}$

SHELXL-2014/7 (Sheldrick, 2014)

$\sum w\left(F_{o}^{2}-F_{c}{ }^{2}\right)^{2}$

$1497 / 0 / 72$

1.153

1469 data; $I>2 \sigma(I), R 1=0.0150, w R 2=0.0365$

all data; $R 1=0.0153, w R 2=0.0368$

$w=1 /\left[\sigma^{2}\left(F_{o}{ }^{2}\right)+(0.0187 P)^{2}+0.1107 P\right]$

where $P=\left(F_{o}^{2}+2 F_{c}^{2}\right) / 3$

0.605 and $-0.540 \mathrm{e}^{-3}$

$0.159 \mathrm{e}^{-3}$

TABLE 4: Atomic coordinates and equivalent isotropic displacement factors $B_{\text {eq }}$ obtained by single crystal (bold) and powder (italic) X-ray diffraction of the Rietveld refinement of Figure 5.

\begin{tabular}{|c|c|c|c|c|c|}
\hline Atoms & Sites & $x$ & $y$ & $z$ & $B_{\mathrm{eq}}$ \\
\hline \multirow{2}{*}{$\mathrm{Zn}$} & \multirow{2}{*}{$4 \mathrm{e}$} & $0.46626(2)$ & $0.16559(2)$ & $0.83731(2)$ & $0.577(4)$ \\
\hline & & $0.46711(14)$ & $0.16514(8)$ & $0.83638(14)$ & $2.939(30)$ \\
\hline \multirow{2}{*}{$\mathrm{Ca}$} & \multirow{2}{*}{$2 \mathrm{a}$} & $0.00000(0)$ & $0.00000(0)$ & $0.00000(0)$ & $0.575(5)$ \\
\hline & & $0.00000(0)$ & $0.00000(0)$ & $0.00000(0)$ & $2.729(49)$ \\
\hline \multirow{2}{*}{$\mathrm{O} 1$} & \multirow{2}{*}{$4 \mathrm{e}$} & $0.53207(10)$ & $0.18022(6)$ & $0.19014(12)$ & $0.743(11)$ \\
\hline & & $0.53231(57)$ & $0.18189(32)$ & $0.18346(58)$ & $3.029(93)$ \\
\hline \multirow{2}{*}{$\mathrm{O} 2$} & \multirow{2}{*}{$4 \mathrm{e}$} & $0.33939(10)$ & $-0.04234(6)$ & $0.24622(11)$ & $0.781(11)$ \\
\hline & & $0.33799(53)$ & $-0.04301(33)$ & $0.24307(52)$ & $3.155(99)$ \\
\hline \multirow{2}{*}{$\mathrm{O} 3$} & \multirow{2}{*}{$4 \mathrm{e}$} & $0.16285(10)$ & $0.12494(6)$ & $0.76040(11)$ & $0.813(11)$ \\
\hline & & $0.16318(56)$ & $0.12393(30)$ & $0.76207(52)$ & 2.804(93) \\
\hline \multirow{2}{*}{$\mathrm{O} 4$} & \multirow{2}{*}{$4 \mathrm{e}$} & $0.03722(11)$ & $-0.15929(6)$ & $0.73424(12)$ & $0.922(11)$ \\
\hline & & $0.03638(53)$ & $-0.15875(29)$ & $0.73272(53)$ & $3.549(90)$ \\
\hline $\mathrm{H} 1$ & $4 \mathrm{e}$ & $0.475(3)$ & $0.120(2)$ & $0.237(3)$ & $3.3(4)$ \\
\hline $\mathrm{H} 2$ & $4 \mathrm{e}$ & $0.326(3)$ & $0.0511(19)$ & $0.378(4)$ & $3.6(5)$ \\
\hline $\mathrm{H} 3$ & $4 \mathrm{e}$ & $0.123(4)$ & $0.117(2)$ & $0.623(4)$ & $4.4(6)$ \\
\hline $\mathrm{H} 4$ & $4 \mathrm{e}$ & $0.162(4)$ & $-0.1709(16)$ & $0.741(4)$ & $3.1(5)$ \\
\hline H5 & $4 \mathrm{e}$ & $0.024(3)$ & $0.2276(19)$ & $0.262(3)$ & $3.1(5)$ \\
\hline
\end{tabular}

\section{Conclusion}

Submicronic and micronic sized calcium zincate was successfully synthesized using the Hydro-Micromechanical milling route. This technique can provide homogeneous calcium zincate crystals with tailored sizes and high purity (>99\%) and is produced at high industrial production rate, in a minimum residence time, without the need to use alkaline solutions or high temperature. The possibility of switching to a continuous synthesis makes this process scalable industrially. Two grades of HMMS materials were characterized and compared to other calcium zincate prepared using the HTS and HCS methods. Whatever the calcium zincate synthesis protocol, the materials obtained always crystallize in the same monoclinic lattice; this clarifies the confusion of the existing literature around the chemistry and structure of calcium zincate. Moreover, only the particle size distribution of these calcium zincate compounds differs, but not their shape: tetragonal crystal growth. Furthermore, using the HMMS method during $144 \mathrm{~s}$ of retention time, which is very fast regarding $24 \mathrm{~h}$ of most of the classical methods, can lead to particle size distribution below $1 \mu \mathrm{m}$. Such high-surface 
area calcium zincate is very attractive for applications in which surface area matters, for example, catalysis (biodiesel production) and electrochemistry ( $\mathrm{Zn}$-based batteries).

\section{Conflicts of Interest}

The authors declare that there are no conflicts of interest regarding the publication of this paper.

\section{Acknowledgments}

Vincent Caldeira would like to thank La Fondation de France Grant no. 0049328 and CNRS Grant no. 113815 for the financial support of his Ph.D. thesis. Mr. S. COINDEAU and T. ENCINAS from CMTC (Grenoble Technological Platform, France) are also acknowledged for their precious help in the understanding and measurement of X-ray powder diffraction characterization.

\section{References}

[1] R. P. Hamlen, A. R. R. Brainard, P. A. Frank et al., "Method of forming calcium zincate powder and electrode," US 3607409 A, 1967.

[2] J. M. Rubio-Caballero, J. Santamaría-González, J. MéridaRobles, R. Moreno-Tost, A. Jiménez-López, and P. MairelesTorres, "Calcium zincate as precursor of active catalysts for biodiesel production under mild conditions," Applied Catalysis B: Environmental, vol. 91, no. 1-2, pp. 339-346, 2009.

[3] J. M. Rubio-Caballero, J. Santamaría-González, J. MéridaRobles et al., "Calcium zincate derived heterogeneous catalyst for biodiesel production by ethanolysis," Fuel, vol. 105, pp. 518$522,2013$.

[4] Ž. Kesić, I. Lukić, D. Brkić et al., "Mechanochemical preparation and characterization of $\mathrm{CaO} \cdot \mathrm{ZnO}$ used as catalyst for biodiesel synthesis," Applied Catalysis A: General, vol. 427-428, pp. 58-65, 2012.

[5] I. Lukić, Ž. Kesić, S. Maksimović et al., "Kinetics of sunflower and used vegetable oil methanolysis catalyzed by $\mathrm{CaO} \cdot \mathrm{ZnO}$," Fuel, vol. 113, pp. 367-378, 2013.

[6] N. M. Gómez-Ortíz, W. S. González-Gómez, S. C. De la RosaGarcía et al., "Antifungal activity of $\mathrm{Ca}[\mathrm{Zn}(\mathrm{OH}) 3] 2 \cdot 2 \mathrm{H} 2 \mathrm{O}$ coatings for the preservation of limestone monuments: an invitro study," International Biodeterioration and Biodegradation, vol. 91, pp. 1-8, 2014.

[7] C. Weeks, R. J. Hand, and J. H. Sharp, "Retardation of cement hydration caused by heavy metals present in ISF slag used as aggregate," Cement and Concrete Composites, vol. 30, no. 10, pp. 970-978, 2008

[8] R. A. Sharma, "Physico-chemical properties of calcium zincate," Journal of the Electrochemical Society, vol. 133, no. 11, pp. 22152219, 1986.

[9] R. Stahl and H. Jacobs, "Crystal structure of $\mathrm{CaZn}_{2}(\mathrm{OH})_{6.2} \mathrm{H}_{2} \mathrm{O}$," Zeitschrift für Anorganische und Allgemeine Chemie, vol. 623, pp. 1287-1289, 1997.

[10] X.-M. Zhu, H.-X. Yang, X.-P. Ai, J.-X. Yu, and Y.-L. Cao, "Structural and electrochemical characterization of mechanochemically synthesized calcium zincate as rechargeable anodic materials," Journal of Applied Electrochemistry, vol. 33, no. 7, pp. 607612, 2003.
[11] H. Yang, H. Zhang, X. Wang, J. Wang, X. Meng, and Z. Zhou, "Calcium zincate synthesized by ballmilling as a negative material for secondary alkaline batteries," Journal of the Electrochemical Society, vol. 151, no. 12, pp. A2126-A2131, 2004.

[12] S. Wang, Z. Yang, and L. Zeng, "Study of calcium zincate synthesized by solid-phase synthesis method without strong alkali," Materials Chemistry and Physics, vol. 112, no. 2, pp. 603606, 2008.

[13] C. S. Xavier, J. C. Sczancoski, L. S. Cavalcante et al., "A new processing method of $\mathrm{CaZn}_{2}(\mathrm{OH})_{6} \cdot 2 \mathrm{H}_{2} \mathrm{O}$ powders: photoluminescence and growth mechanism," Solid State Sciences, vol. 11, no. 12, pp. 2173-2179, 2009.

[14] M. L. Tong and X. Y. Liu, "Preparation and electrochemical performances of calcium zincate synthesized by microwave method," Advanced Materials Research, vol. 236-238, pp. 868871, 2011

[15] S. Li and Y. Y. Zhou, "Preparation of tetragonal and hexagonal calcium zincate," Applied Mechanics and Materials, vol. 130-134, pp. 1454-1457, 2012.

[16] F. Lacoste and J. Thiel, "Method for manufacturing calcium zincate crystals, and the uses thereof," WO2016156749 (A1), 2016.

[17] G. M. Sheldrick, "A short history of SHELX" Acta Crystallographica Section A: Foundations of Crystallography, vol. 64, no. 1, pp. 112-122, 2008.

[18] H. M. Rietveld, "Line profiles of neutron powder-diffraction peaks for structure refinement," Acta Crystallographica, vol. 22, no. 1, pp. 151-152, 1967.

[19] H. M. Rietveld, "Rietveld refinement round robin. I. Analysis of standard X-ray and neutron data for $\mathrm{PbSO}_{4}$," Acta Crystallographica, vol. 25, pp. 589-610, 1992.

[20] G. Caglioti, A. Paoletti, and F. P. Ricci, "Choice of collimators for a crystal spectrometer for neutron diffraction," Nuclear Instruments, vol. 3, no. 4, pp. 223-228, 1958.

[21] J. Rodriguez-Carvajal, M. T. Fernandez-Diaz, and J. L. Martinez, "Neutron diffraction study on structural and magnetic properties of $\mathrm{La}_{2} \mathrm{NiO}_{4}$," Journal of Physics: Condensed Matter, vol. 3, no. 19, pp. 3215-3234, 1991.

[22] J. Rodríguez-Carvajal, "Recent advances in magnetic structure determination by neutron powder diffraction," Physica B: Physics of Condensed Matter, vol. 192, no. 1-2, pp. 55-69, 1993. 

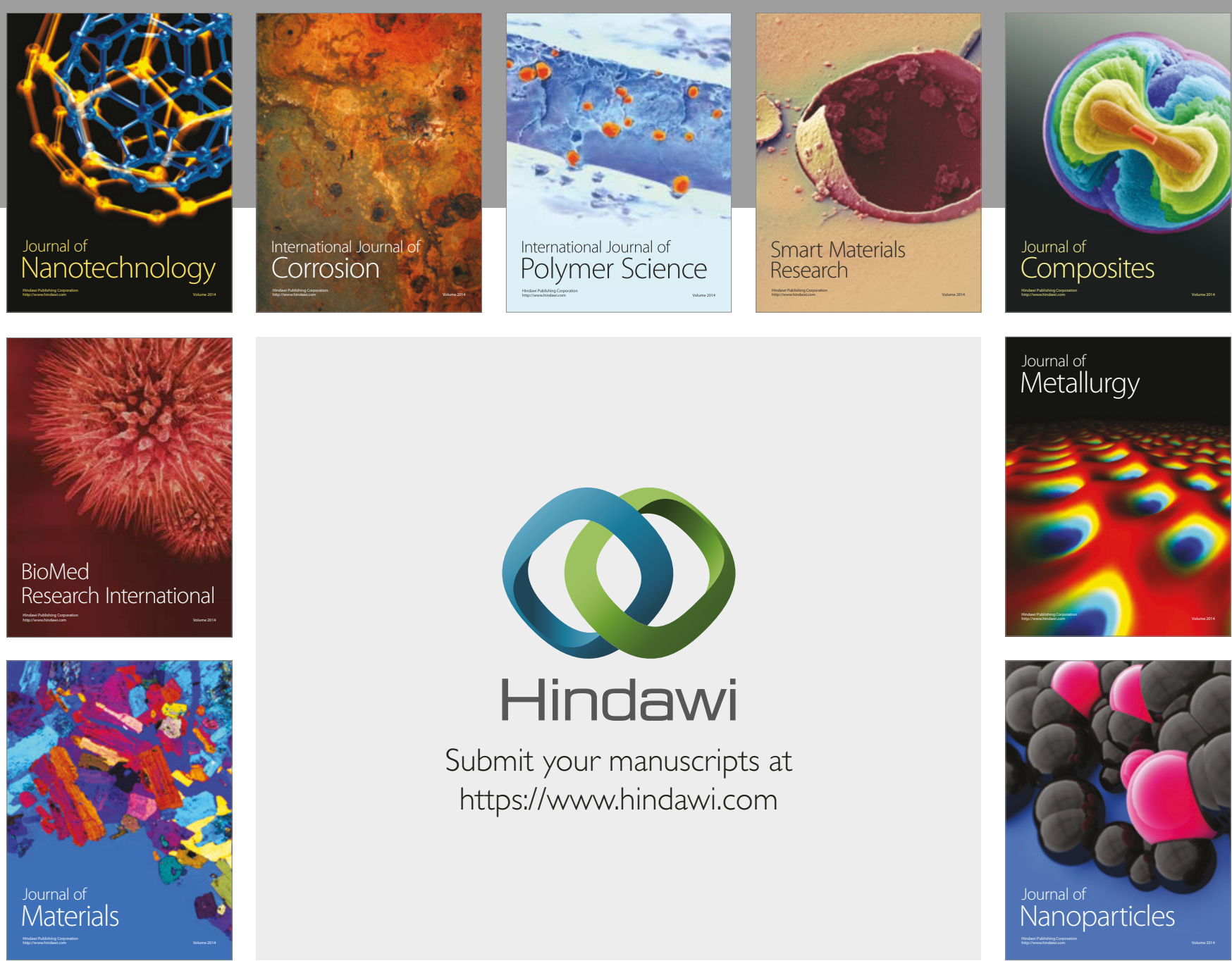

\section{Hindawi}

Submit your manuscripts at

https://www.hindawi.com
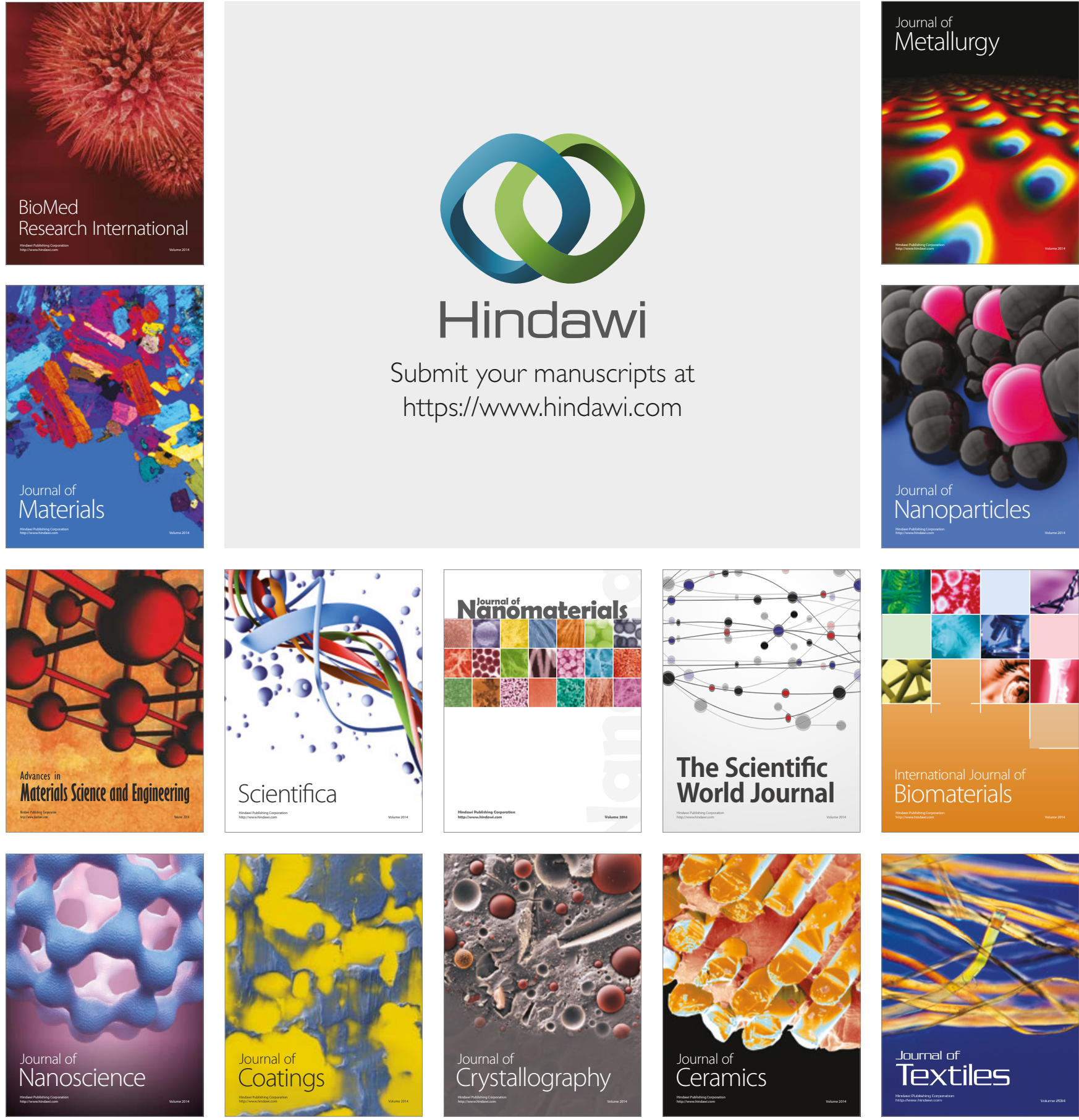

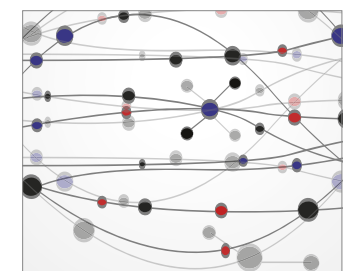

The Scientific World Journal
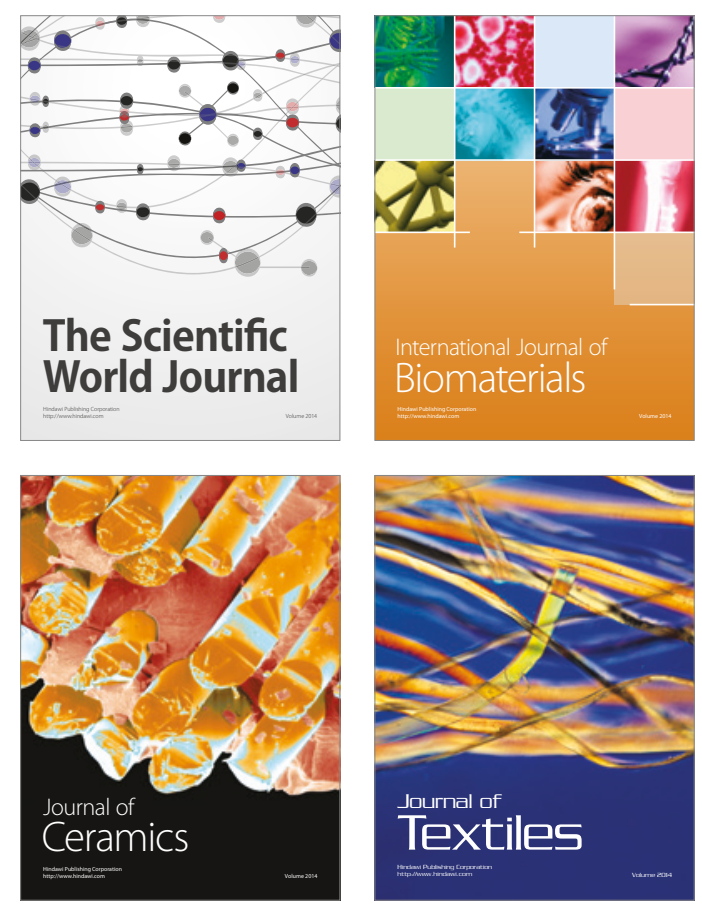